\title{
Focal and Segmental Proliferative Glomerulonephritis
}

National Cancer Institute

\section{Source}

National Cancer Institute. Focal and Segmental Proliferative Glomerulonephritis. NCI

Thesaurus. Code C123180.

Glomerulonephritis characterized by proliferation of endothelial or mesangial cells, affecting the glomeruli in a focal and segmental pattern. 